\title{
Museos Históricos de Norpatagonia (Argentina): el pasado colonial revisitado ${ }^{1}$
}

\author{
Laura Aylén Enrique \\ Universidad Nacional de San Martín, San Martín, Província de Buenos Aires, \\ Argentina \\ E-mail: aylenle@yahoo.com.ar
}




\section{Resumen}

Entendemos que los museos contribuyen a generar, reproducir, fomentar, así como también a tergiversar y silenciar determinados elementos o dimensiones en los procesos de construcción del pasado local. En el norte de la Patagonia argentina la cercanía entre las ciudades de Carmen de Patagones y Viedma, ubicadas en dos provincias diferentes - Buenos Aires y Río Negro, respectivamente - nos posibilita plantear un abordaje comparativo e investigar las narrativas fundacionales que se elaboran y difunden desde sus museos históricos. Ambas ciudades evocan como hito fundante el establecimiento del Fuerte del Carmen a fines del periodo colonial, un punto de avance y control español. Nos interesa indagar en los modos en que sus museos, en tanto dependencias estatales que responden a jurisdicciones diferentes, muestran el pasado colonial para conocer las estrategias mediante las cuales se construyen los recuerdos y olvidos en las versiones oficiales de los orígenes locales.

Palabras clave: Narrativas Fundacionales. Museos Históricos. Construcción del Pasado. Patagonia Argentina.

\section{Resumo}

Entendemos que os museus contribuem para gerar, reproduzir, promover, além de distorcer e de silenciar, certos elementos ou dimensões nos processos de construção do passado local. No norte da Patagônia, a proximidade entre as cidades de Carmen de Patagones e Viedma, localizadas em dois estados diferentes, - Buenos Aires e Río Negro, respectivamente-, nos permite propor uma abordagem comparativa e investigar as narrativas fundacionais que são elaboradas e disseminadas a partir de seus museus históricos. Ambas as cidades evocam como marco fundador o estabelecimento de Fuerte del Carmen no final do periodo colonial como ponto de avanço e de controle da Espanha. Estamos interessados em investigar as maneiras pelas quais seus museus, como agências estatais que respondem a diferentes jurisdições, mostram o passado colonial para conhecer as estratégias pelas quais as memórias e o esquecimento são construídos em versões oficiais de origens locais.

Palavras-chave: Narrativas Fundacionais. Museus Históricos. Construção do Passado, Patagônia Argentina. 


\section{Introducción}

T a ciudad de Carmen de Patagones, al sur de la provincia de Buenos LAires, y la de Viedma, al este de la provincia de Río Negro, se encuentran ubicadas en el noreste de la Patagonia argentina. Están separadas por el río Negro, que recorre 730 kilómetros de oeste a este del país, desde la confluencia de los ríos Neuquén y Limay hasta desaguar en el océano Atlántico, a 30 kilómetros aproximadamente de las ciudades referidas. Aunque responden a estados provinciales distintos y por ende son administradas por municipios diferentes - los partidos Carmen de Patagones y Adolfo Alsina, respectivamente -, se hallan geográficamente muy próximas y evocan un momento fundacional común que remite a la instalación del Fuerte del Carmen, a finales del periodo colonial. El Fuerte se estableció inicialmente en la margen sur - actual Viedma - a comienzos de 1779 pero pocos meses más tarde tuvo que ser trasladado a la margen norte - hoy Carmen de Patagones -, más elevada sobre el nivel del mar, debido a una inundación que asoló la zona.

Este origen en común es también el fundamento de la creación de la "Comarca Viedma-Patagones", un modelo de gestión compartida que considera más relevante la cercanía geográfica y la consecuente cotidianeidad entre la ciudad más austral de la provincia de Buenos Aires - Carmen de Patagones - y la capital de la provincia de Río Negro - Viedma - que su pertenencia a jurisdicciones provinciales diferentes. Teniendo en cuenta esta filiación de antaño, a mediados de la década de 1980 el gobierno de Raúl Alfonsín había impulsado el traslado de la capital del país a un futuro Distrito Federal que abarcaría Viedma, Carmen de Patagones y zonas aledañas mediante la ley 23.512 (1987) en el marco del "Proyecto Patagonia". Aunque se creó el "Ente para la 
Construcción de la Nueva Capital - Empresa del Estado" (ENTECAP), dicha migración nunca se concretó debido a que la situación sociopolítica nacional dio prioridad a otros asuntos de índole económica. No obstante, la ley nunca fue derogada por el Congreso de la Nación, e incluso, la Convención Constituyente de 1994 habilitó la instalación de la capital fuera de la Ciudad de Buenos Aires y la posterior provincialización de ésta.

Más allá de las semejanzas compartidas, en cada localidad se han desarrollado diversas políticas de memoria en torno a la construcción de las "marcas de ciudad" ${ }^{2}$, es decir, de las imágenes representativas que se seleccionaron para identificarlas. Así, cada una de las versiones acerca de los orígenes de las ciudades es legitimada mediante distintos recursos pero la selección de lo que se elige "recordar" sobre el pasado siempre es efectuada en función de intereses presentes (Prats, 1997; Candau, 2002; Endere, 2009; Connerton, 1989 [2007]). Entendemos que la heterogeneidad de organismos estatales que participan en la gestión del patrimonio de Carmen de Patagones y Viedma en las diferentes escalas jurisdiccionales incide en los elementos que se escogen para contar el surgimiento de cada una de las localidades.

Aquí nos proponemos indagar en las narrativas fundacionales que se construyen en ambas ciudades con respecto al pasado colonial desde una óptica particular, la de sus museos históricos. El centrarnos en las estrategias que desarrollan estas instituciones estatales que dependen de entidades que responden a provincias diferentes, pero a la vez se encuentran tan próximas, nos brinda la posibilidad de llevar a cabo un abordaje comparativo inusual que resulta de interés para comprender los modos en que operan las selecciones de los eventos del pasado que se escogen para recordar y difundir. En este sentido, los museos en tanto dependencias estatales cumplen un rol esencial en la negociación de los sentidos que se ponderan, se deforman o se silencian al recrear los comienzos de las localidades, establecer determinados lazos con ellos y propagarlos. Además, dado que su gestión depende en gran medida de la coyuntura política, de la disponibilidad de recursos de diferente tipo - económicos, humanos, técnicos, informativos - y de los intereses y la participación de los distintos grupos y actores sociales implicados, examinar los modos en que los museos muestran el pasado colonial 
en cada localidad nos permite conocer relatos sobre el patrimonio que también son legitimados por los distintos estamentos estatales. En este trabajo consideramos el Museo Histórico Regional "Emma Nozzi" de Carmen de Patagones y el Museo Provincial Antropológico-Histórico "Gobernador Eugenio Tello" de Viedma, centrados en una perspectiva histórica de dichas ciudades. Aunque diversos investigadores han abordado las interrelaciones entre la conformación del estado nación y la creación de museos a fines del siglo XIX (Schmilchuck, 1987; Dujovne, 1995; Podgorny, 2005; Blasco, 2007), existen pocos estudios sobre el museo histórico de Carmen de Patagones (Vezub, 2012; Bustos; Dam, 2012) y ninguno sobre el de Viedma, y en particular, no han sido explorados en relación con los procesos de reconstrucción de los orígenes de dichas ciudades.

\section{Hace 238 Años: el Fuerte del Carmen}

El Fuerte "Nuestra Señora del Carmen" se erigió en la costa sur del río Negro, a unos 30 kilómetros de su desembocadura, el 22 de abril de 1779 bajo el mando de Francisco de Viedma. La instalación del fortín materializaba la continuación de un plan de avance y consolidación del dominio español en sus colonias frente a eventuales incursiones de otras potencias europeas en los extensos territorios que se desplegaban tan alejados de Buenos Aires, la capital del recientemente creado Virreinato del Río de la Plata (1776) (De Paula, 1985)³ [Figura 1]. Poco tiempo después de su nacimiento, el desborde del río y una importante inundación ocurrida el 13 de junio de ese mismo año obligaron a trasladar al Fuerte del Carmen a una zona más elevada, en la margen barrancosa del norte del río Negro, donde perduró hasta fines del siglo siguiente, cuando el avance militar de Julio A. Roca conllevó que ya no fuera necesario sostenerlo en pie. 


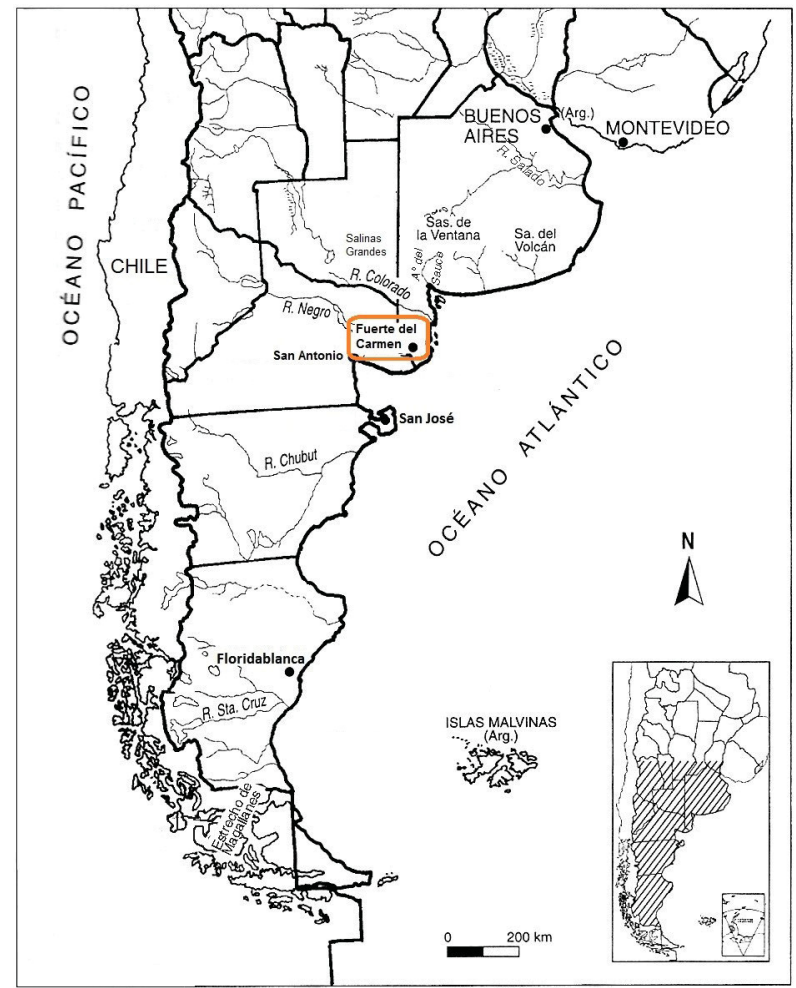

Figura 1: Mapa de la región de estudio con ubicación de los sitios mencionados Fuente: Adaptada de Nacuzzi (2008)

Esa ubicación estratégica y la colaboración de los grupos indígenas de la zona le permitieron a su creciente población subsistir más allá de las dificultades para mantenerse en un sitio tan alejado de la mirada de las autoridades centrales y con dilatadas comunicaciones - en su mayoría por vía marítima - con el centro administrativo virreinal. En marzo de 1827 el poblado fue atacado por tropas del Imperio de Brasil que se encontraba en conflicto con las Provincias Unidas del Río de la Plata, pero la invasión fue resistida y aun hoy se conmemora el triunfo local del 7 de marzo.

Con el paso del tiempo, el caserío inicial se convirtió en la ciudad de Carmen de Patagones, independizándose de Mercedes de Patagones, que luego sería renombrada como Viedma en 1878, cuando ésta pasó a ser la capital de la Gobernación de la Patagonia. Viedma prosiguió siendo capital del Territorio Nacional del Río Negro de manera informal 
desde 1884 cuando se la Gobernación se suprimió (Ley n. 1.532) hasta que en 1955 se creó la provincia de Río Negro. No obstante, recién en 1973, la ciudad de Viedma se consolidó formalmente como la capital provincial (Ley Provincial n. 852). Además de la inundación de 1779 que forzó el desplazamiento del Fuerte del Carmen a la margen norte del río, Viedma sufrió otras inundaciones, siendo la de fines de julio de 1899 la más recordada, cuando el agua rompió las defensas de la ciudad e ingresó al pueblo, manteniéndose en su máximo nivel durante tres días consecutivos. Únicamente el Colegio de Salesianos logró resistir la inundación que incluso obligó a la relocalización de las autoridades locales bajo el mando de José Tello, cuyo gobierno tuvo que establecerse temporalmente en Carmen de Patagones y se negó a trasladarse a Choele-Choel como había dispuesto el gobierno nacional. Esto no sólo constituye un ejemplo más de cómo el río Negro ha estructurado el desarrollo de ambas ciudades e influido en sus vínculos a lo largo de los más de doscientos años de historia en común que se evocan, sino también forma parte del fundamento de afirmaciones de los viedmenses como "a lo colonial se lo llevó el agua".

Nos interesa el hecho de que tanto Carmen de Patagones como Viedma consideren un origen en común que se remite al periodo colonial a pesar de que no se ha conservado ningún acta fundacional, las instalaciones consecutivas del fuerte "trasladado" producto de la inundación se efectuaron con varios meses de diferencia, y los poblados fueron conocidos con nombres distintos durante la mayor parte de su historia. Para reflexionar acerca de la construcción de ese nacimiento compartido nos basamos en el concepto de "narrativas fundacionales" propuesto por Rappaport (1998 [1990]) con respecto a su caso de estudio del grupo indígena colombiano Nasa. Dicha noción nos posibilita dar cuenta de la selección, creación y resignificación del pasado, poniéndolas en juego con los procesos de elaboración y trasmisión de los relatos que explican el surgimiento de cada localidad. De esta manera evitamos referirnos a ellos como "mitos de origen", término que generalmente alude al carácter mítico como una invención o ficción (Vernant, 1982), y soslayamos falsas dicotomías entre los aspectos históricos o míticos (Sahlins, 1997 [1985]; Hill, 1988; Turner, 
1988) Así, la idea de "narrativas fundacionales" le permitió a Rappaport avanzar en la problematización del concepto de "tradiciones inventadas" que habían propuesto Hobsbawm y Ranger (2002 [1983]) para abordar ciertas prácticas con funciones simbólicas que, al repetirse, buscan inculcar determinados valores y cristalizarlos. Al respecto, también Briones (1994) sostuvo que la noción de "tradiciones inventadas" no podía extrapolarse a los procesos de construcción del pasado de los grupos subalternos sin adoptar los recaudos pertinentes.

Entendemos que las "narrativas fundacionales" constituyen modos creativos de seleccionar y rearticular algunos aspectos de las configuraciones previas y, simultáneamente son capaces de incorporar nuevos elementos en función de los intereses presentes. Por ello, indagar acerca de cómo se cuenta el surgimiento de Carmen de Patagones y Viedma mediante esta aproximación nos ofrece la posibilidad de evidenciar su carácter coyuntural y dinámico, cristalizado en determinada selección de elementos que se articulan de una forma particular y que los museos se encargan de difundir. Tal como hemos señalado en trabajos previos (Enrique, 2014; 2015), las políticas y planificaciones patrimoniales nacionales y provinciales contribuyen a (re)crear determinados pasados y difundirlos, silenciando voces alternativas. No obstante la proximidad y el evento fundante construido en común, el pasado colonial es considerado de manera diferencial en estas ciudades. Mientras Carmen de Patagones se estructura urbanística y socialmente en torno al centro histórico costero de corte colonial donde se encuentran entre otros, los vestigios del fuerte, en Viedma el eje organizacional se centra en la costanera norte y en los alrededores de la plaza Alsina, colindante con la "manzana histórica" de los Salesianos, en un sector diferente a donde habría estado ubicado el antiguo fuerte - actual Centro Cultural - y el germen poblacional.

Consideramos que explorar las narrativas fundacionales que se ponen de manifiesto en los museos de Carmen de Patagones y Viedma nos ofrece un punto de vista nuevo sobre los modos en que desde los organismos estatales se elige contar los orígenes de estas ciudades, construyendo determinados recuerdos y dejando de lado otros. En este sentido, es importante destacar la cantidad y diversidad 
de museos existentes en dichas localidades dado que entre ambas cuentan con seis museos estatales para un total de 73.322 habitantes - repartidos en 20.533 y 52.789, respectivamente - (INDEC, 2010), sin contar la población de cada uno de los partidos de los cuales son cabecera - Carmen de Patagones y Adolfo Alsina. Esta amplia oferta museística se expresa principalmente en Viedma en la multiplicidad de actores sociales implicados en la gestión patrimonial producto de los distintos organismos gubernamentales de los que dependen los museos. Así, por orden de aparición, el Museo Histórico y Arqueológico "Gobernador Eugenio Tello" (1971) depende de la provincia de Río Negro, el Museo Histórico y Religioso Salesiano "Cardenal Cagliero" (1980) de la orden religiosa, el Museo Tecnológico del Agua y del Suelo "Ing. O. Casamiquela" ( 1984) del Departamento Provincial de Aguas, y el Museo Gardeliano “Lisandro Segovia” (1996) ${ }^{4}$ de gestión privadamunicipal. Aquí nos centraremos en el primero de ellos teniendo en cuenta la incidencia que puede tener su enfoque y contenido en relación con la construcción del pasado colonial. En el caso de Carmen de Patagones hallamos dos museos estatales: el Histórico Regional "Emma Nozzi" ( 1951) y el de la Prefectura Naval Argentina - que fue inaugurado en 1995 y funciona dentro del predio de Prefectura desde 2001. Nos detendremos sólo en el primero que se encuentra ubicado en la calle J. J. Biedma 64, en su intersección con el pasaje Del Muelle, en razón de su relación con la temática colonial. La ciudad también cuenta con el Museo Privado de Arqueología Regional "Julio Gironde".

El Consejo Internacional de Museos - ICOM, por su nombre en inglés - (2007) define el museo como "una institución permanente, sin fines de lucro, al servicio de la sociedad y abierta al público, que adquiere, conserva, estudia, expone y difunde el patrimonio material e inmaterial de la humanidad con fines de estudio, educación y recreo", lo cual es ratificado a nivel nacional por la sede argentina del organismo. Esta descripción hace hincapié en la perduración en el tiempo, el no obtener ganancias económicas a cambio y en que los visitantes puedan educarse, lo cual no implica deba ser bajo un marco de formato estrictamente formal ni que estos no disfruten de la experiencia. Con respecto a la función del museo se destacan tres ejes fundamentales: 
la conservación, la investigación y la exhibición. En este sentido, la cuestión de brindar un "servicio a la sociedad y abierta al público" constituye un aspecto a considerar en este trabajo de manera particular dado que el Museo Antropológico-Histórico “Gobernador Eugenio Tello" de Viedma permaneció cerrado al público desde el año 2010 hasta finales de 2017. En 2008 se había intentado que fuera declarado "monumento nacional" mediante un proyecto impulsado por el senador nacional de Río Negro Pablo Verani, pero finalmente no prosperó. Por lo que, tras cumplir cuarenta años en actividad, en 2010 se lo cerró "temporariamente" para que el edificio en el que funcionaba - en el sector céntrico de la ciudad, San Martín 263 - volviera a ser utilizado como sede municipal, tal como ocurría durante la década de 1970. En consecuencia, se dejó a los pobladores de la ciudad sin el acceso al único museo provincial que tenía - ya que, como mencionamos, los demás dependen de otras instituciones - e imposibilitados de aprovechar una de las colecciones arqueológicas más importantes de la provincia. Asimismo, la falta de un edificio limitó las actividades desarrolladas por quienes aún trabajaban en el museo, que debieron generar estrategias de difusión alternativas, incrementando las tareas "puertas afuera" a través de charlas en las escuelas, capacitaciones docentes y trabajos de investigación con otros organismos. Poco después, a fines de 2013 se inauguró el Instituto Provincial de Historia Rionegrina "Mario Franco" (Ley Provincial n. 4.851) con el objeto de investigar, preservar, asesorar y difundir la historia provincial y se ubicó en el edificio de Garrone 39 donde se pretendía trasladar el Archivo Histórico Provincial que se encuentra en el museo. Aunque no se lo planteó como una sustitución, el museo fue despojado de su espacio físico y quedó reducido a un depósito tanto de los objetos que albergaba como del material del archivo y la biblioteca, que no fue posible consultar de forma normal por casi una década.

En lo que respecta al museo histórico de Carmen de Patagones, nació el 14 de julio de 1951 con el nombre de "Francisco de Viedma" en homenaje al fundador del fortín prístino. Fue creado por el entonces intendente Carlos Tessari en colaboración con la Comisión Municipal de Cultura en el salón del Colegio San José y poco después fue trasladado a la Municipalidad. Las primeras colecciones del museo 
fueron donadas por los descendientes de las familias fundadoras de la localidad respondiendo a las iniciativas de Emma Nozzi, quien fuera su directora durante más de cuatro décadas e impulsora de diversos proyectos patrimoniales en la ciudad ${ }^{5}$. Por ello, en el año 2002 el museo cambió su nombre para homenajearla, y tanto ella como Tessari son recordados en un panel en la sala inicial mediante una síntesis histórica de sus aportes a la preservación del patrimonio local. En 1988 el museo dejo de ser municipal al convertirse en dependencia del Banco de la Provincia de Buenos Aires (Ordenanza Municipal n. 1.376/86) y se trasladó a la denominada "casa histórica", sede del banco hacia 1884, gracias a las gestiones de Nozzi y Elva Roulet, vicegobernadora de la provincia de Buenos Aires. Roulet (1987, p. 62) señalaba que, desde su fundación, el museo cumplía "la función de vincular a las generaciones jóvenes con el pasado heroico del Fuerte rionegrino" y destacaba el estímulo que Nozzi realizaba en esa dirección, lo cual se consolidó con la creación de la Comisión para la Defensa de los Bienes Culturales Maragatos en 1985. Más allá del traslado y la modificación con respecto al organismo de dependencia, desde 1988 funciona en el museo el Archivo Histórico Municipal. Allí pueden consultarse tres libros copiadores de notas de la Comandancia Militar de Patagones, uno de ellos correspondiente a la etapa 1781-1795, aunque el repositorio reúne principalmente documentación del siglo XIX y XX, publicaciones periódicas y algunas fotografías. A fines de 2016, tras una importante inversión monetaria en la infraestructura del museo, el reemplazo de las autoridades del municipio y del poder ejecutivo provincial así como de los directivos del Banco Provincia del cual depende el museo, iniciaron negociaciones para desligarlo del mismo y volver a traspasarlo al ámbito municipal (Namuncurá, 2016; APP, 2016).

\section{Recuerdos y Olvidos en los Museos “Tello" (Viedma) y "Nozzi" (Carmen De Patagones)}

El museo "Eugenio Tello" debe su nombre a quien fuera gobernador de la provincia durante la inundación de 1889 e impulsor de la ciudad de Viedma como su capital. En función de la situación de su virtual cierre que hemos descripto, buscamos reconstruir los contenidos de las 
salas basándonos en folletería y fotografías, complementándolo con información recogida mediante entrevistas al personal del museo. El folleto donde se da cuenta de la última exhibición bajo el título "Nuestra Muestra Permanente" [Figura 2] presenta una fundamentación de la exposición estructurada en tres ejes: 1) los procesos económicos y sociales centrados en las estrategias indígenas de supervivencia y reproducción, 2) su "desenvolvimiento cultural" y 3) los cambios producto de "la llegada del español". Este recorrido cronológico comenzaba por la Sala "Poblamiento Americano" haciendo hincapié en la ocupación del territorio actual de la provincia de Río Negro y se incluían tanto gráficos explicativos de las teorías de poblamiento como también ciertos aspectos de la organización social de los grupos indígenas y sus herramientas líticas. La sala "Contactos interétnicos" mostraba la distribución geográfica de los grupos indígenas mediante dos mapas con el objeto de plasmar la circulación, contactos y heterogeneidad de los grupos. Luego, desde una perspectiva evolucionista se exponía el “proceso de complejización de la estructura económica, sociopolítica y cultural de los pueblos originarios" entre los siglos XVII y XIX asociados al intercambio de ganado y a la incorporación del caballo, con base en producción bibliográfica especializada sobre la cual no existe consenso entre los investigadores (Palermo, 1988; Mandrini, 1992; Nacuzzi, 1998). Esto se vinculaba con la sección siguiente dedicada a los "Circuitos comerciales y relación con el blanco", en la que se explicaba la ruptura en el equilibrio de las relaciones entre los "pueblos tehuelche-mapucheblanco" como producto de la expansión ganadera desde Buenos Aires y del incremento de los intercambios de la región pampeana con Chile por el traslado de ganado. 

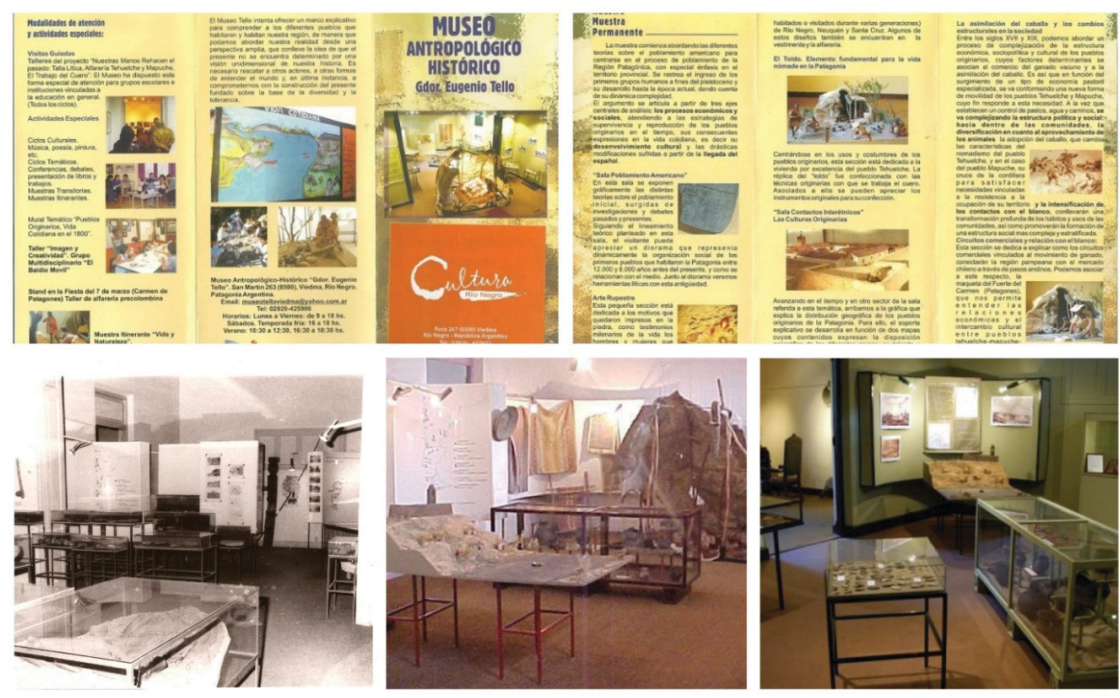

Figura 2: Museo "Tello". Folleto de difusión "Nuestra Muestra Permanente" y fotografías de las salas referidas a grupos indígenas, de izquierda a derecha: etapa fundacional (década de 1970) y vista de la maqueta del Fuerte (2003 y 2006, respectivamente)

Fuente: Museo Histórico y Arqueológico “Gobernador Eugenio Tello”

El folleto culminaba con el objetivo del museo: ofrecer un marco explicativo que ponga en duda "la idea de que el presente no se encuentra determinado por una visión unidimensional de nuestra historia". Para lo cual se advertía sobre la necesidad de "rescatar a otros actores" y de construir el presente a partir de la diversidad y la tolerancia, en relación con lo que destacamos la relevancia que se otorgaba a los grupos indígenas a una escala semejante a la dada a los hispanocriollos. Sin embargo, aunque se incorporó la referencia a "pueblos originarios" pluralizando la referencia previa a "el indio", se continuó propiciando una visión homogénea sobre "el blanco", masculino y uniforme.

Si consideramos este folleto en relación con otro de 1981, mecanografiado en lugar de en colores, encontramos que la secuenciación de las salas no había variado sustancialmente. El folleto de 1981 comenzaba con la presentación del museo, sus colecciones y sus dos salas, dedicadas a los "aspectos fundamentales de la historia del poblamiento indígena y europeo en Patagonia y, particularmente, 
en Río Negro". En la "Sala Antropológica" se exhibían las teorías de poblamiento americano acompañadas de "cráneos de las siguientes razas primitivas: pámpidos, fuégidos y láguidos", "diferentes tipos de deformaciones craneanas practicadas por dichos grupos" y "algunos esqueletos de individuos tehuelches", todo lo cual responde a corrientes teóricas de la época que ya no están vigentes. En los últimos años los restos humanos que estaban alojados en el museo han sido restituidos a las comunidades indígenas correspondientes tal como establece la ley nacional 25.517 (2001), y paralelamente se han reemplazado las referencias a las "razas" con el término "pueblos originarios", con lo cual las salas del museo debieron ser readecuadas. El criterio evolucionista que ancla a los indígenas a un pasado remoto se encontraba presente también en las menciones a las herramientas atribuidas a "cazadores y recolectores no especializados que vivieron aproximadamente entre el 9.000 A.C. y el 1.000 A.C.". Las puntas de flecha, raspadores, boleadoras, hachas, placas grabadas, agujas, punzones y retocadores de hueso eran adjudicadas a otros grupos de cazadores especializados que habitaban el interior patagónico. Se explicaba que los indígenas del norte de la Patagonia estuvieron más sujetos a las influencias de los demás grupos, de quienes adoptaron la cerámica, y fueron presionados o absorbidos por los cazadores especializados, de ellos descenderían los tehuelches o patagones - divididos entre septentrionales y meridionales -, luego afectados por "la invasión araucana". Este tipo de enfoques han sido revisados y cuestionados desde la década de 1990, tanto el denominado proceso de araucanización (Mandrini y Ortelli 1995, Ortelli 1996) como las adscripciones étnicas (Nacuzzi 1998). En el folleto de difusión se posicionaba implícitamente a los indígenas en un rol de "buen salvaje", afectados de forma negativa por "la llegada del europeo [que, una vez más como actor social homogéneo] complicó el cuadro étnico y cultural", acelerando la araucanización, la incorporación del caballo, e introduciendo "los vicios". La época colonial tardía era caracterizada con la disminución del ganado cimarrón que llevó a la incursión española en los territorios indígenas y desencadenó “los sangrientos malones de fines del siglo XVIII y del XIX", lo cual también ha sido problematizado como estrategias de negociación interétnica (Crivelli, 
1991). Los grupos indígenas se habrían desintegrado posteriormente, arrinconándose sus miembros en sitios inhóspitos, de forma tal que debieron incorporarse al resto de la población: "Hoy, solo unos pocos conservan la lengua, formas artesanales de trabajo y una ceremonia: el Nguillatun o Camaruco".

La "Sala histórica" se estructuraba en tres periodos: "la primera centuria", "la campaña al desierto" y "los tiempos contemporáneos", de los cuales nos interesa el primero por su relación con el surgimiento del "Fuerte y población de Ntra. Sra. del Carmen" como "germen inicial de las actuales ciudades de Viedma y Patagones". Sin embargo, en el folleto se ha borrado la instalación primaria del fuerte en la margen sur del Río Negro centrándose en el devenir posterior y señalando que sólo en Patagones "se construyó un fuerte como el que se exhibe en la maqueta [Figura 2], aunque no llegó a estar totalmente concluido. En la banda sur, inundable, se encontraban los establecimientos agrícolaganaderos". Recién al pasar al siguiente periodo se mencionaba que "la población del sur" era denominada "Mercedes" al convertirse en asiento de las autoridades de la Gobernación de la Patagonia en 1878. Se destacaba la "vida mísera" de los pobladores pioneros del fuerte, "abandonados [por] las autoridades coloniales primero y patrióticas después", hasta el auge del puerto hacia 1820 - como consecuencia del bloqueo del puerto de Buenos Aires - y se hacía alusión a los "tiempos heroicos" del triunfo sobre los brasileños en 1827. Se describía la situación de estos primeros cien años como una "economía de auto abastecimiento" debido al aislamiento en que se hallaban, en la que se mantenía "un activo comercio con los indígenas, llegando a ser un importante centro de racionamiento", defendido por pobladores e "indios amigos".

De forma complementaria, también consideramos el análisis del trabajo de campo llevado a cabo por Spoliansky (1997) entre 1995 y 1996 en relación con las descripciones contenidas en la Serie Divulgación B1 del museo de 1974 mediante el cual advertía que la exhibición había sido "la misma" durante esos últimos veintitrés años. La autora señalaba escasas modificaciones en el discurso museístico a mediados de la década de 1990, tales como la eliminación de dos carteles sobre "raza" 
y "cultura" a fines de 1995 que, no obstante, no habrían implicado una modificación del punto de vista general. Spoliansky sostenía que la preeminencia del enfoque arqueológico en la sala sobre los grupos indígenas habría continuado adscribiéndolos al pasado, reforzado por la inclusión de fotografías antiguas de indígenas, mapas de distribución de los grupos en distintas fases históricas - en clara alusión a los propuestos por Casamiquela (1965, entre otros) -, y la exposición de restos humanos ${ }^{6}$. De esta manera, la autora daba cuenta de la perspectiva evolucionista del museo según la cual indígenas, independientemente de su asiento temporal, eran considerados "primitivos", como parte de un tiempo mítico, previo y por fuera de nuestro tiempo occidental. Al circunscribirlos en un "presente etnográfico" en el que además se los vinculaba a prácticas mortuorias y huesos, se separaba a los indígenas en la sala "antropológica" del periodo colonial que inauguraba la sala "histórica". En relación con esto, el análisis de fotografías históricas nos posibilita notar las semejanzas a lo largo de los años y los efectos del progresivo cambio en las teorías museográficas en la organización interna de las salas y en la articulación entre ellas, propendiendo a generar espacios más abiertos y con menor acumulación de objetos [Figura 2].

Spoliansky (1997, p. 85), asimismo, resaltaba la atención otorgada a la maqueta del Fuerte del Carmen como eje del discurso del museo "Tello" como una manera de demostrar "la importancia de la era colonial en la historia local, a través de este símbolo de la primera ocupación blanca en la Patagonia". Ese énfasis también se observa en el folleto "Nuestra Muestra Permanente" que mencionamos [Figura 2], donde se presentaba la maqueta del "Fuerte del Carmen (Patagones)" sin hacer alusión a la instalación inicial sobre la margen viedmense del río Negro. En el folleto, además, se destacaba el toldo como un "elemento fundamental para la vida nómade en la Patagonia" y "la vivienda por excelencia del pueblo Tehuelche", lo cual mostraba concordancia con la preponderancia otorgada en el museo, y se advertía que la réplica exhibida había sido confeccionada mediante técnicas tradicionales de trabajo con cuero [Figura 3]. 


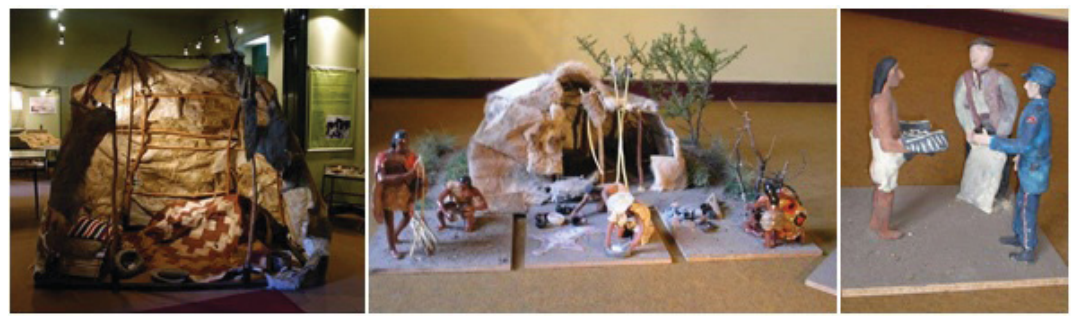

Figura 3: Réplica de un toldo indígena y maqueta de la vida cotidiana en las tolderías con detalle de representación anexa

Fuente: Museo Histórico y Arqueológico “Gobernador Eugenio Tello"

Es interesante tener en cuenta aquí otra maqueta que representa la vida en las tolderías indígenas y complementa las del fuerte y del toldo, como parte de la muestra itinerante del museo [Figura 3]. En ella se pueden apreciar a distintos indígenas llevando a cabo diferentes actividades como la fabricación de herramientas y armas, el procesamiento de alimentos y el tratamiento de los cueros de animales para confeccionar vestimentas y viviendas. En dichas "escenas" se presentan los diversos atuendos que utilizaban las mujeres y los hombres así como también detalles en la construcción de los toldos. Asimismo, se representó una pareja interactuando con un niño y, de forma periférica, es decir, más alejado del toldo, un intercambio entre un indígena y dos personajes caracterizados como hispanocriollos, uno de ellos soldado.

Por otro lado, al considerar el Museo Histórico Regional "Emma Nozzi" de Carmen de Patagones también encontramos referencias al fortín colonial y los primeros tiempos del poblado. Tras la celebración de la Fiesta de la Soberanía Patagónica en 2015 se incorporó a la exhibición una maqueta Fuerte del Carmen [Figura 4], realizada por el artista plástico Alexis Balbuena. Se confeccionó en una escala 1:50 a partir de los planos del fuerte de 1780 elaborados por el ingeniero español José Pérez Brito y datos del relato de viaje del naturalista francés Alcide d'Orbigny (APP, 2015). En función de sus grandes dimensiones, ya que mide dos metros y medio por cada lado se colocó en una sala aparte. En la maqueta se observan distintas escenas de la vida cotidiana del Fuerte como prácticas de tiro, limpieza y aseo, manejo del ganado, vigilancia, así como también destacamos la presencia de indígenas y mediadores como lenguaraces, que se acercaban al establecimiento para intercambiar bienes, obtener y ofrecer información y llevar a cabo negociaciones. 
Asimismo, se incluyó la torre que originariamente fue campanario de la capilla del fuerte y atalaya para vigilar los alrededores, construida en 1780 con bloques irregulares de piedra arenisca compactada y consolidada, conocida localmente como "tosca mora". Cuando en 1880 se decidió la demolición del fuerte, se preservó la torre como testimonio del mismo y aún continúa en pie, protegida tempranamente a escala nacional al declararla "monumento histórico nacional" en 1942 (Decreto n. 120.411).

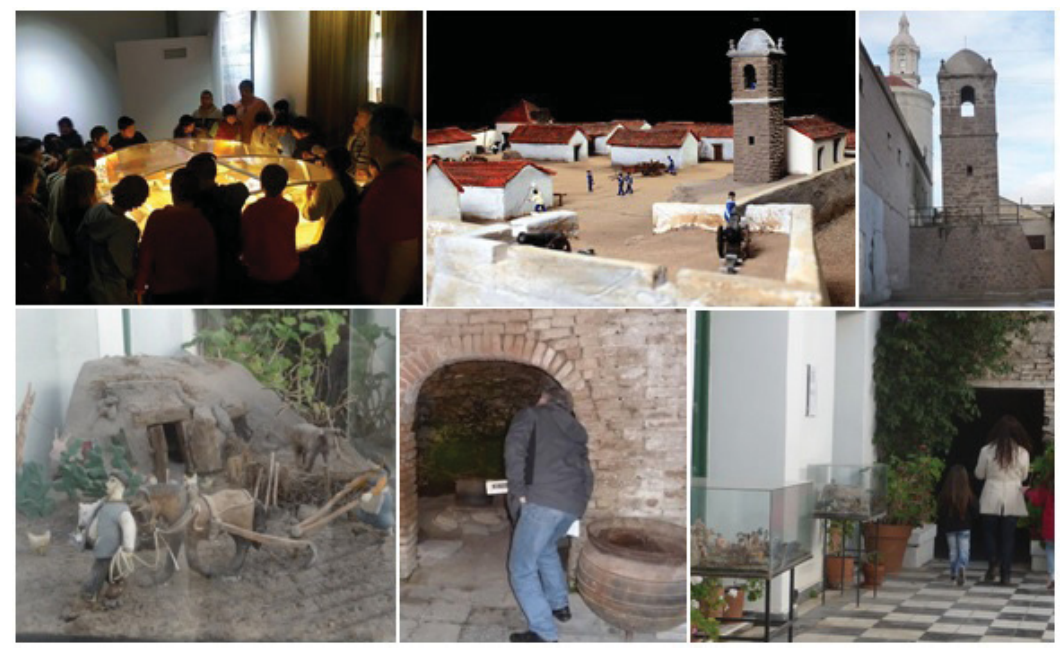

Figura 4: Museo "Nozzi". Arriba, maqueta del Fuerte del Carmen y la torre de la capilla del fuerte en la actualidad. Abajo: "Cueva maragata" en el patio del museo, su interior con referencia de escala humana y detalle de la maqueta en la que se la representa

Fuente: Museo Histórico Regional "Emma Nozzi”

En el interior del museo, las salas y el sentido de circulación para recorrerlas se atienen a un criterio cronológico que comienza por el patio colonial y continúa secuencialmente. Luego, para salir, es necesario hacer el camino inverso volviendo a pasar por cada sala. Nos detendremos en el patio y la primera de las salas que se refieren a "la etapa pionera", entre 1779 y 1820. En el fondo del patio se puede apreciar una "cueva maragata", cuya denominación deriva del lugar de procedencia de la gran mayoría de esos pobladores pioneros: la comarca de la Maragatería en España. Este tipo de cuevas fueron cavadas en la barranca del río por los primeros contingentes poblacionales de 
españoles que arribaron al área y buscaron guarecerse cuando vieron incumplidas las promesas del rey Carlos III de proveerles viviendas y herramientas (Casanueva, 2013; Enrique, 2014). La arenisca del terreno facilitó las tareas de excavación y el formato de entrada única y la distribución interna les ofreció a los habitantes protección del viento y del frío de la región. Debido a su microclima fresco interno, consecuencia en parte de la baja altura de la abertura de ingreso, con el paso de los años varias de estas cuevas se acondicionaron para ser utilizadas como despensas y almacenamiento de alimentos y bebidas. En la actualidad la cueva ubicada en el predio del museo Nozzi presenta un muy buen estado de conservación, su acceso se encuentra restringido al público y hacia 1900 se construyó una bóveda de ladrillo para evitar el desgranamiento de sus paredes [Figura 4]. En 2003 fue declarada "monumento histórico" junto con la Casa Histórica del Banco de la Provincia de Buenos Aires donde hoy se encuentra el museo y la casa anexa que fuera del cardenal Juan Cagliero (Decreto Nacional n. $401 / 2003$ ). Se ha incluido una de estas cuevas en la primera maqueta de una serie de cuatro, ubicadas en el patio para dar cuenta de escenas de la vida colonial [Figura 4]. En esta primera representación de la cueva utilizada como residencia se han caracterizado a dos pobladores pioneros dando cuenta de su vestimenta típica y realizando tareas agrícolas. La imagen está acompañada de un breve texto explicativo titulado "Familia maragata labradora".

La siguiente maqueta carece de referencias, títulos y textos explicativos, lo que no parece ser una omisión casual sino una alusión entendida como evidente o más bien una invitación a la reflexión ya que se encuentra dedicada a la vida cotidiana de un grupo indígena en un toldo, lo cual permite establecer comparaciones con la cueva como vivienda. Como en el caso de la maqueta del museo "Tello", los personajes muestran los atuendos de los indígenas - que difieren según sus sexos - y diversas actividades como la preparación y cocción de alimentos, la construcción de herramientas y armas, el procesamiento de cueros y el manejo del ganado, distinguiéndose la presencia de caballos. También se observan interacciones con niños que podrían ser grupos familiares y, más alejado del toldo, tienen lugar negociaciones 
e intercambios con algunos individuos vestidos como criollos y de tono de piel más claro, lo que da cuenta de los mestizajes presentes en estos enclaves fronterizos.

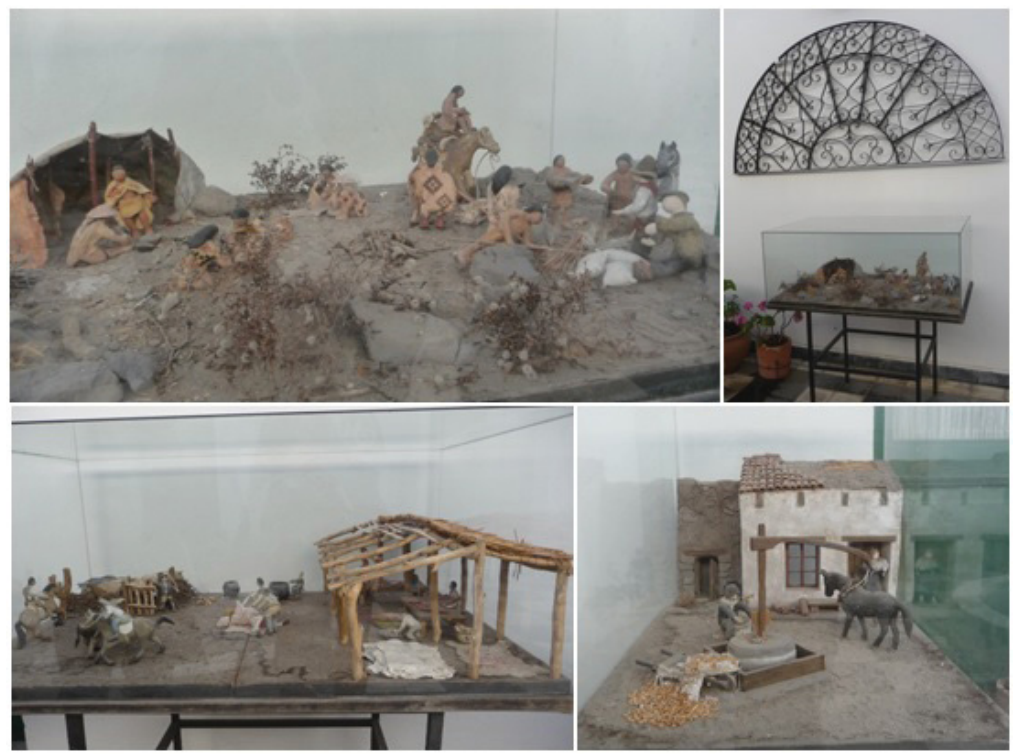

Figura 5: Arriba, maqueta que representa la vida en un toldo indígena y ubicación del modelo sin texto explicativo. Abajo, maquetas restantes referidas al funcionamiento del saladero y de una tahona Fuente: Fotografías de la autora de este artículo

La tercera y cuarta maquetas están dedicadas a una etapa posterior de principios del siglo XIX cuando comienza a reactivarse económicamente la vida en el poblado y están basadas en parte del relato de D'Orbigny (1829). Hacia 1820 los saladeros adquirieron gran importancia comercial y Patagones contaba tanto con salinas cercanas que le proveían del mineral para el tratamiento de los alimentos como con el acceso al ganado vacuno a través del intercambio con los indígenas - a costos menores que en los saladeros bonaerenses y litoraleños -, lo que se sumaba a la abundante mano de obra barata por los presos que eran deportados al fuerte. En lo que respecta a la cuarta maqueta, se ha caracterizado una práctica frecuente en el poblado colonial, la molienda del trigo para la posterior elaboración del pan. Sin embargo, a pesar de la alusión a una escena de la vida hogareña que se representa, el texto adjunto aclara que la mujer viste "ropa de 
fiesta maragata". En el mismo sentido, el rancho es descripto como de adobe y de techo a dos aguas, aunque en el modelo sólo se observa un declive al frente.

En el interior de las salas descubrimos algunos elementos y detalles que posibilitan a los visitantes establecer lazos con las escenas representadas, tales como herramientas - por ejemplo, los morteros en manos de los indígenas -, vestimenta u otros artefactos como las ollas que aparecen utilizadas por los españoles. Asimismo, se ha colocado una olla en el interior de la "cueva maragata" del patio para recrear el ambiente y el tipo de actividades que tuvieron lugar en ella. Tal como se puede observar en la Figura 6, algunas de estas ollas formaron parte de las primeras exposiciones en las salas del museo, cuando éste aún dependía de la municipalidad en la década de 1970.

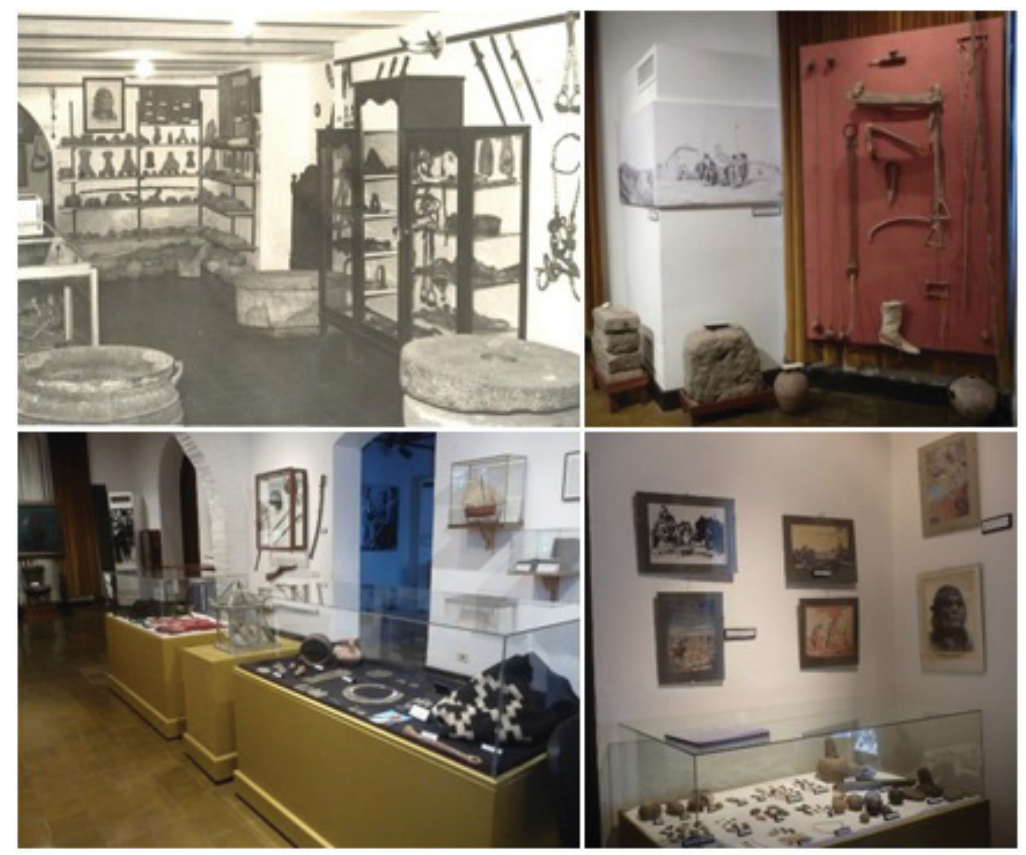

Figura 6: Sala referida a los tehuelches en el museo municipal (década de 1970) y referencias a los primeros pobladores españoles y a grupos indígenas en las salas actuales (2013)

Fuente: Museo Histórico Regional "Emma Nozzi”

El traslado del museo al nuevo edificio a finales de la década de 1980 modificó su configuración interna al ampliar el espacio disponible 
y, en las décadas siguientes, las salas fueron despojándose de la abundancia de bienes exhibidos, reduciendo la extensión de los textos que los acompañaban y ofreciendo espacios de circulación mayores como mostramos que ocurrió en el museo "Tello", en concordancia con los cambios en los enfoques teórico-metodológicos de la museología (Fernández, 1999). En este sentido, no obstante, Spoliansky (1997) señalaba en la década de 1990 una continuación en la acumulación de objetos y la caracterización de los grupos indígenas semejante a las que se advierten en la fotografía de 1970.

Hoy el recorrido de las salas comienza con dos mapas que nos sitúan en la región patagónica: uno donde podemos ubicar los “establecimientos españoles y etnías aborígenes a fines del s. XVIII" y otro que presenta el "escenario de la actuación de Luis Piedra Buena". Cabe destacar la ausencia de fechas - que son brindadas por el guía en caso de que se efectúe una visita guiada - y la referencia sólo a establecimientos españoles patagónicos sin señalar los fortines cercanos al río Salado, por ejemplo, que datan de la misma época. Asimismo, se han utilizado ciertos etnónimos como "gününa-kune" o la distinción entre tehuelches "septentrionales" y "meridionales" que como mencionamos han sido cuestionados ya desde la década de 1990 - de forma paralela al uso de otros como "selknam" y "yámanas" - que reemplazaron la denominación con sesgo colonizador de "ona" en Tierra del Fuego.

Como mostramos en la Figura 6, la etapa colonial está representada en esta primera sala donde es posible encontrar referencias a los grupos indígenas identificados como tehuelches junto con imágenes antiguas y piezas líticas trabajadas - puntas de flecha, boleadoras, morteros, etc. De esta manera, los indígenas parecen estar adscriptos al pasado ya que no existen menciones concretas en otras salas más actuales. No obstante, resulta posible establecer vínculos con el presente teniendo en cuenta una vitrina cercana donde se exhiben artesanías textiles y orfebres asociadas a la "cultura mapuche". Sin embargo, esta exposición se encuentra en el centro del salón junto con otra sobre los atuendos de españoles, por el contrario, el resto de la muestra está dispuesta en las paredes de la habitación. Por ende, la relación entre pasado- 
presente no es directa, e incluso se dificulta, como consecuencia de la asociación de las referencias a dos grupos indígenas diferentes: los tehuelches y los mapuches.

Una síntesis de esta exposición se presenta en el folleto de divulgación del museo en el que "la etapa pionera" es caracterizada por la fundación del Fuerte del Carmen “[...] en pleno territorio tehuelche [...] facilitada por un acuerdo previo entre el Virrey de Vértiz y el Cacique Chanel". En este sentido, se subraya la colaboración y las negociaciones con los grupos indígenas que contribuyeron a la subsistencia del fuerte, cuya población, aislada, no habría sido atacada por malones debido a "[...] la progresiva armonía de intereses con las tribus patagónicas". En el folleto esta etapa concluye con la crisis generada por los cambios políticos producto de la revolución de mayo de 1810 que llevaron a Patagones al borde de su desaparición y al desconocimiento de las autoridades de Buenos Aires hasta 1815.

La exhibición sobre los grupos indígenas de la zona se complementa más adelante en la misma sala con elementos de vestimenta y uso de los "gauchos" criollos tales como boleadoras, instrumentos de labranza y de manejo ecuestre. Estos objetos están acompañados de una serie de representaciones históricas del Fuerte del Carmen a principios del siglo XIX, entre las que se encuentra la reproducción de la litografía de Alcides d' Orbigny de 1829 donde se puede ver la interacción entre indígenas y españoles próximos a la construcción, e incluso visualizar la torre del fuerte. También se exponen varias pinturas referidas a la navegación marítima y fluvial, lo cual da cuenta de las vías de comunicación de la época y de la importancia del puerto, y se las vincula con la lucha contra los invasores brasileños de 1827 y el comandante Luis Piedrabuena, nacido en Carmen de Patagones. En relación con esto, se incluye una ampliación de una fotografía de 1888 en la cual se destaca la presencia del "último sobreviviente del regimiento de esclavos libertos que participara valientemente en la gesta del 7 de marzo de 1827, Felipe 'la Patria'”. Estas referencias continúan discursivamente luego en una pequeña sala contigua dedicada a la campaña militar de Julio A. Roca y a la sociedad de la época en la cual se destacan varios paneles acerca del cambio en la política de frontera con los indígenas 
y extractos de solicitudes hechas a militares de campaña pidiendo niñas y niños indígenas como sirvientes para los "vecinos del Carmen". Asimismo, hallamos información sobre la instalación de la misión salesiana a fines del siglo XIX en el edificio que hoy ocupa el museo.

Por último, el discurso museístico se complementa con la visita guiada a la casa "La Carlota" situada a pocas cuadras del museo, en la intersección de las calles Bynon y Mitre. La casa, que perteneció a Carlota Martínez de Ibáñez, descendiente de pobladores pioneros, consta de tres habitaciones ambientadas como sala de entrada, dormitorio y cocina, con muebles y otros elementos de la época donados por los vecinos. Así, en contraste con la falta de un edificio propio que enfrentó el museo "Eugenio Tello" de Viedma, el museo "Emma Nozzi" de Carmen de Patagones cuenta para su funcionamiento con la denominada "casa histórica" del banco y la "cueva maragata" anexa, la casa colonial "La Carlota" y, de forma más reciente, con la llamada "Casa Cagliero", inmuebles que han sido declarados parte del patrimonio argentino por el estado nacional mediante el Decreto n. 401/2003.

\section{Consideraciones Finales}

A lo largo del trabajo mostramos que los museos históricos de Carmen de Patagones y Viedma contribuyen a generar narrativas fundacionales y reconstruir los orígenes de modo semejante, centrándose en el Fuerte del Carmen y un pasado evocado en común. Si bien la heterogeneidad de organismos estatales involucrados en el manejo del patrimonio afecta las políticas patrimoniales resultantes, los dos museos examinados han logrado trascender algunas de las limitantes consecuentes organizando diversas actividades en conjunto, como muestras y talleres. No obstante, cabe señalar la falta de articulación entre las políticas patrimoniales desarrolladas en ambas ciudades, más allá de los esfuerzos realizados en torno a eventos tales como la conmemoración del aniversario de la fundación los 22 de abril de cada año, del triunfo sobre los invasores brasileros los 7 de marzo en el marco de la Fiesta de la Soberanía Patagónica, y, específicamente en relación con nuestra problemática, la noche de los museos algunos 18 de mayo. De esta manera, se pone de manifiesto la incidencia de las 
divisiones administrativas y jurisdiccionales en la organización y en las decisiones sobre quiénes gestionan los bienes antiguos y el patrimonio local - atendiendo a su conservación, investigación y difusión, lo cual afecta también cómo se resuelve la financiación de dichas gestiones.

El trabajo de Quijada (2012) acerca de los "museos de frontera"7 constituye un sugestivo punto de partida para avanzar en el futuro en la reflexión sobre los museos históricos de Carmen de Patagones y Viedma en relación con otros museos ubicados en localidades que se formaron en el contexto de las fronteras hispano-indígenas al sur y suroeste de la ciudad de Buenos Aires (Enrique, 2014; 2015). Como señalamos, el Fuerte del Carmen, aunque alejado geográficamente de los denominados "fortines del Salado" - hoy provincia de Buenos Aires -, formaba parte también de los enclaves fronterizos que las autoridades españolas instalaron a finales del periodo colonial. Quijada (2012, p. 172) sostiene que el origen de esas localidades bonaerenses "en el imaginario se asoció al enfrentamiento entre dos culturas disímiles y desniveladas" y se basó en una "población que a lo largo del siglo XIX era 'otra', [y que] a finales de ese siglo se convirtió en 'nosotros', fuera este último reconocido o no". En ese contexto, entendemos que los procesos de identificación y producción de "sentidos de pertenencia" a los que apelan los museos estarían basados en el desarrollo de narrativas fundacionales que expliquen la construcción de dicho "nosotros" y el establecimiento de nexos con el pasado colonial y el devenir de la población pionera. En nuestro caso de estudio en particular, el museo Nozzi es el que mayor atención otorga y mayor superficie destina al pasado colonial, especialmente si consideramos también su patio interno con la "cueva maragata" y los anexos de las casas "Cagliero" y "La Carlota". Nos preguntamos acerca de cómo incide la falta de un espacio físico en la conservación del patrimonio local, en la investigación que debiera llevar a cabo el museo y en su difusión. Tras comparar las transformaciones históricas de las salas notamos que, progresivamente, se han orientado a que los visitantes se interroguen acerca de qué vínculos establecen con el pasado local, apuntando a aquellos aspectos con los que pudieran sentirse identificados e incorporando nuevas estrategias museográficas. A futuro sería preciso evaluar qué 
repercusiones han tenido estas intenciones en los públicos de los museos y qué relaciones construyen los habitantes con la historia local. En esta dirección, generar mayores correlaciones entre el guion interno del museo y los recursos disponibles fuera de él posibilitaría un mayor aprovechamiento la persistencia física en el entorno urbano de gran parte de los vestigios materiales del pasado colonial. Esto puede contribuir, además, a problematizar el hilo cronológico que explica la exhibición y replantear el sentido de la circulación de los visitantes para recorrer el museo, evitando la obligación de reiterar trayectos. En los dos museos analizados las exhibiciones se complementan - o complementaban en el caso del museo "Tello" - con la difusión que su personal realiza mediante muestras itinerantes, talleres, conferencias, participación en las conmemoraciones locales y la realización de actividades específicas en las escuelas de cada ciudad. ¿Sería preciso que el museo, carente de un edificio, además se reinventara mediante estrategias tecnológicas que avanzaran más en el camino realizado con las actividades "puertas afuera"? La disponibilidad de un espacio físico para funcionar no se restringe a una cuestión presupuestaria en tanto consideramos que, aunque de diferente tenor, las problemáticas de financiamiento que afectan a estos dos museos - con repercusiones semejantes en última instancia - constituyen principalmente la consecuencia de decisiones políticas que trascienden la disponibilidad o no de los fondos necesarios para el adecuado funcionamiento de los establecimientos. Las diversas estructuras administrativas de las que dependen escogen atender prioridades entre las cuales, en general, no se encuentran la conservación, la investigación ni la difusión patrimonial. Esto se convierte en un problema si se olvida que resulta fundamental elaborar las planificaciones de las políticas estatales en materia patrimonial cuando aún es posible tomar las decisiones pertinentes, dado que como mencionamos al comienzo del trabajo, el patrimonio no es un recurso renovable (APN, 2001; Holtorf, 2004). En el caso que nos ocupa, los interrogantes planteados por Prats (1997) veinte años atrás en torno a quién/es poseen la legitimidad para gestionar el patrimonio y en nombre de quién/es lo hace/n continúan vigentes en un contexto en el cual están en juego aspectos que atañen a los procesos identitarios de los 
pobladores de dos ciudades distintas, asociados a bienes materiales de más de doscientos años de antigüedad. Esto también pone en cuestión un potencial rol pasivo de los museos como depósitos de patrimonio que los debates museológicos han echado por tierra desde hace décadas y cómo eso se relaciona con la necesidad o no de contar con un espacio físico para funcionar.

Por otro lado, cabe destacar el interés de parte de quienes gestionan los museos a escala local de narrar versiones del pasado con una fuerte impronta regional, incorporando en las salas de exposición los resultados de las últimas investigaciones en la materia, lo cual resulta difícilmente sustituible. Sin embargo, es preciso permanecer atentos a que la necesaria inclusión de "otras voces" que puedan dar cuerpo a esas versiones no se limite a la única consideración de los "expertos", sino que comprenda las múltiples perspectivas de los diferentes grupos sociales implicados. Tanto en el museo "Tello" como en el "Nozzi" observamos un énfasis diferente con respecto a los orígenes que podría ser utilizado para promover una mirada crítica de parte de los visitantes e incitar la problematización de sus presupuestos. Pensamos que este acento diferencial contribuiría al reconocimiento de la "multivocalidad" en los discursos de los museos que, retomando a Merriman (2000), podría evidenciar una multiplicidad de versiones de la historia en relación con las coyunturas que las generaron.

\section{Notas}

1 Agradezco especialmente la atenta predisposición y colaboración del personal de los museos de Carmen de Patagones y Viedma, así como también los cuidados comentarios de la Dra. Mónica Rotman. Este trabajo fue realizado con el apoyo de los subsidios otorgados por la Universidad de Buenos Aires (UBACyT W215) y el Consejo Nacional de Investigaciones Científicas y Técnicas (CONICET-PIP 0641).

2 La idea también conocida como "city-marketing" (Torres Ribeiro y Sánchez García 1996, Fernández y Paz 2005) surgió en la década de 1990 como una estrategia para generar una imagen representativa de la ciudad que resultara de utilidad para la gestión gubernamental, aunque con un enfoque predominantemente economicista y turístico que priorizaba atraer inversiones de capital. Álvarez et al. (2005) han presentado un análisis de los beneficios y las dificultades relacionadas con la gestión de la comarca Viedma-Patagones.

3 A comienzos de 1779 se había instalado el Fuerte de San José de la Candelaria en el golfo de San José - al norte de la actual Península Valdés, en la provincia de Chubut - desde donde la expedición se internó con rumbo norte en busca de 
una ubicación más adecuada para establecerse y mejor provista de agua dulce. Al año siguiente también se emplazó el Fuerte de Floridablanca (1780) al sur, en las cercanías de la bahía de San Julián, en la actual provincia de Santa Cruz. Aunque parte de la población de San José fue trasladada al Fuerte del Carmen pocos meses más tarde, dicho puesto perduró hasta 1810 cuando fue atacado por indígenas. Por su parte, el Fuerte de Floridablanca fue abandonado poco tiempo después de su instalación, en enero de 1784, al acatar la Real Orden del virrey Vértiz de 1783 de despoblar los establecimientos patagónicos (Senatore, 2007).

4 El museo fue rebautizado con el nombre de su creador en el año 2000, año de su muerte y en el aniversario del $65^{\circ}$ aniversario del fallecimiento de Carlos Gardel.

5 Para mayores detalles sobre la biografía de Nozzi consultar Pupio (2016).

6 Algunos de los cuales ya hemos mencionado que fueron restituidos.

7 La autora ha caracterizado cuatro tipos de lo que denomina "museos de frontera": 1) los pot-pourri, donde se presenta una variedad de objetos, 2) museos culturalistas, con énfasis en los aspectos científicos y, en particular, los arqueológicos, 3 ) museos estetizantes, en los cuales en las exhibiciones prima lo estético, y 4) museos historizantes, donde la historia estructura el discurso expositivo en el cual "el indio aparece como el personaje histórico protagonista de un proceso en el tiempo" (Quijada, 2012, p. 170).

\section{Referências}

ADMINISTRACIÓN DE PARQUES NACIONALES (APN). Política de manejo de recursos culturales. Resolución 115/01. 2001. Disponible en: https://www.sib.gov.ar/archivos/mrc-normativas-apn.pdf. Acceso en: 3 mayo 2017.

ÁLVAREZ, Liliana, Susana GUERRERO y Carina OPAZO. La agencia de desarrollo microregional Viedma-Carmen de Patagones: Ausencias y presencias. Pilquen, [S.l.], n. VII, 2005. Disponible en: http://www.scielo. org.ar/pdf/spilquen/n7/n7a07.pdf. Acceso en: 26 abr. 2017.

\section{AGENCIA PERIODÍSTICA PATAGÓNICA (APP). Presentan una} maqueta que refleja construcciones y vida en el fuerte de Carmen de Patagones, 5 de marzo de 2015. Disponible en: http://www. appnoticias.com.ar/desarro_noti.php?cod=16652. Acceso en: 24 feb. 2017

PATAGONES: Incertidumbre por la decisión del Banco Provincia de Buenos Aires de dejar de sostener el museo, 10 de diciembre de 2016. Disponible en: http://appnoticias.com.ar/app/patagones-incertidumbre-por-ladecision-del-banco-provincia-de-buenos-aires-de-dejar-de-sostener-elmuseo/. Acceso en: 24 feb. 2017.

BLASCO, María E. Los museos históricos en la Argentina entre 1889 y 1943. Historiapolítica.com, 2007. Disponible en: http://historiapolitica. com/datos/biblioteca/blascol.pdf. Acceso en: 3 mayo 2017. 
BRIONES, Claudia. Con la tradición de todas las generaciones pasadas gravitando sobre la mente de los vivos: usos del pasado e invención de la tradición. Runa, Buenos Aires: Instituto de Ciencias Antropológicas, n. 21 , p. 99-129, 1994.

BUSTOS, Jorge y Leonardo DAM. El Museo Histórico Regional “Emma Nozzi" de Carmen de Patagones, Corpus, [S.l.], v. 2, n. 1, 2012. Disponible en: http://corpusarchivos.revues.org/993. Acceso en: 5 jun. 2016.

CANDAU, Joël. La antropología de la memoria. Buenos Aires: Nueva Visión, 2002.

CASAMIQUELA, Rodolfo. Rectificaciones y ratificaciones: hacia una interpretación definitiva del panorama etnológico de la Patagonia y área septentrional adyacente. Bahía Blanca: Universidad Nacional del Sur, 1965.

CASANUEVA, María L. Inmigrantes tempranos: maragatos en la Patagonia argentina. Las cuevas del Fuerte Nuestra Señora de El Carmen. Revista Española de Antropología Americana, Madrid: Universidad Complutense, v. 43, n. 1, p. 111-132, 2013.

CONNERTON, Paul. How societies remember. Cambridge: Cambridge University Press, 2007 [1989].

CONSEJO INTERNACIONAL DE MUSEOS (ICOM). Estatutos del ICOM adoptados durante la 22 ${ }^{\text {a }}$ Conferencia General de Viena. 2007.

Disponible en: http://archives.icom.museum/statutes_spa.pdf. Acceso en: 16 oct. 2015.

CRIVELLI, Eduardo. Malones: ¿saqueo o estrategia? El objetivo de las invasiones de 1780 y 1783 a la frontera de Buenos Aires. Todo es historia, Buenos Aires: Todo Es Historia SA, n. 28, p. 6-32, 1991.

DE PAULA, Alberto. Planeamiento territorial y fortificaciones portuarias en Patagonia y Malvinas, durante el dominio español. Actas del I Seminario "Puertos y Fortificaciones en América y Filipinas", p. 299-347, 1985.

DUJOVNE, Marta. Entre Musas y musarañas: una visita al museo. Montevideo: FCE, 1995.

ENDERE, María Luz. Algunas reflexiones acerca del patrimonio. In: ENDERE, M. y J. PRADO (ed.). Patrimonio, ciencia y comunidad. Olavarría: UNCPBA, 2009. p. 19-48.

ENRIQUE, Laura Aylen. Paisajes difusos del bicentenario: (re) construcción del pasado y del paisaje colonial de la frontera sur. 2014. Tesis (Doctorado) - Facultad de Filosofía y Letras, Universidad de Buenos Aires, Buenos Aires, 2014. 
ENRIQUE, Laura Aylen. Políticas públicas sobre patrimonio colonial y contexto hispano-indígena en el cono sur americano (Argentina). Pasos, Santa Cruz de Tenerife: Universidad de La Laguna, v. 13, n. 1, p. 223-236, 2015.

FERNÁNDEZ, Luis. Introducción a la Nueva Museología. Madrid: Alianza Editorial, 1999.

FERNÁNDEZ, Gabriel y Sergio PAZ. Más allá del marketing de ciudades: hacia una política pública de diseño y gestión de los signos de identificación de ciudad, Scripta Nova, Barcelona: Universidad de Barcelona, v. IX, n. 194- 195, 2005. Disponible en: http://www.ub.edu/ geocrit/sn/sn-194-95.htm. Acceso en: 13 oct. 2016.

HILL, J. (ed.) Introduction: Myth and History. In: HILL, J. (ed.).

Rethinking History and Myth. Urbana: University of Illinois Press, 1988. p. 1-17.

HOBSBAWM, Eric; RANGER, Terence (ed.) La invención de la tradición. Barcelona: Crítica, 2002 [1983].

HOLTORF, Cornelius. Is the past a non-renewable resource? In: R. LAYTON, P. Stone; THOMAS, J. (ed.). Destruction and conservation of cultural property. Londres: Routledge, 2004. p. 286-297.

INSTITUTO NACIONAL DE ESTADÍSTICAS Y CENSOS (INDEC) Censo Nacional de Población, Hogares y Viviendas, 2010. Disponible en: https://www.indec.gov.ar/nivel4_default.asp?id_tema_l=28id_ tema_2=418id_tema_3=135. Acceso: 4 abr. 2018.

MANDRINI, Raúl. Indios y fronteras en el área pampeana (siglos XVI y XIX). Balance y perspectivas. Anuario del IEHS, Tandil: UNICEN, n. VII, p. 59-72, 1992.

MANDRINI, Raúl; ORTELLI, Sara. Repensando viejos problemas: observaciones sobre la araucanización de las pampas. Runa, Buenos Aires: Instituto de Ciencias Antropológicas, n. XXII, p. 135-150, 1995.

MERRIMAN, Nick. The crisis of representation in archaeological museums. In: MCMANAMON, F.; HATTON, A. (ed.). Cultural Resources Management in Contemporary Society. Londres: Routledge, 2000. p. 300-309.

NACUZZI, Lidia. Identidades impuestas. Buenos Aires: Sociedad Argentina de Antropología, 1998.

NACUZZI, Lidia. Repensando y revisando el concepto de cacicazgo en las fronteras del sur de América (Pampa y Patagonia). Revista Española de Antropología Americana, Madrid: Universidad Complutense de Madrid, v. 38, n. 2, p.75-95, 2008. 
NAMUNCURÁ, Nelson El Museo Emma Nozzi pasaría a manos del Municipio, 4 de diciembre de 2016. Disponible en: http://www. noticiasnet.com.ar/61-edicion-impresa/patagones-y-buenos-aires/31174el-museo-emma-nozzi-pasaria-a-manos-del-municipio. Acceso en: 24 feb. 2017

ORTELLI, Sara. La "araucanización" de las pampas: ¿realidad histórica o construcción de los etnólogos? Anuario del IHES, Tandil: UNICEN, n. 11 , p. 203-225, 1996.

PALERMO, Miguel. La innovación agropecuaria entre los indígenas pampeano-patagónicos. Génesis y procesos, Anuario del IEHS, Tandil: UNICEN, n. III, p. 43-90, 1988.

PODGORNY, Irina. La mirada que pasa: museos, educación pública y visualización de la evidencia científica, História, Ciências, Saúde Manguinhos, Río de Janeiro: Fundação Oswaldo Cruz, n. 12, p. 231-264, 2005.

PRATS, Llorenç. Antropología y patrimonio, Barcelona: Ariel, 1997. PUPIO, María Emma Nozzi, School Teacher and Provincial Collector (Buenos Aires, Argentina), HoST - Journal of History of Science and Technology, n. 10, p. 11-32, 2016. Disponible en: DOI: https://doi. org/10.1515/host-2016-0002. Acceso: 3 mar. 2017.

QUIJADA, Mónica. Los museos de frontera de la provincia de Buenos Aires: entre el gliptodonte y el indio poblador, Revista de Indias, Madrid: SCIC, v. LXXII, n. 254, p. 131-176, 2012.

RAPPAPORT, Joanne. The Politics of Memory. Durham: Duke University Press, 1998 [1990].

SAHLINS, Marshall. Islas de Historia. Barcelona: Gedisa, 1997 [1985].

SCHMILCHUK, Graciela (comp.) Museos: Comunicación y Educación. Antología comentada. México: CENIDIAP, 1987.

SENATORE, María. Arqueología e historia en la colonia española de Floridablanca (Patagonia - siglo XVIII). Buenos Aires: Teseo, 2007.

SPOLIANSKY, Vivian. El otro urbanizado: la inscripción de lo indígena en el espacio-tiempo nacional. Tesis de licenciatura inédita. Facultad de Filosofía y Letras, Universidad de Buenos Aires, 1997.

TORRES RIBEIRO, Ana; SÁNCHEZ GRACÍA, Fernanda. City marketing: a nova face da gestão da cidade no final de século. In: REIS, Paula Félix dos et al. (comp.), Política e cultura. Visóes do Passado e perspectivas contemporáneas, São Paulo: Editorial Hucitec, 1996. p. 168-181. 
TURNER, Terence. History, myth, and social consciousness among the Kayapó of central Brazil. In: HILL, J. (ed.). Rethinking History and Myth. Urbana: University of Illinois Press, 1988. p. 195-203.

VERNANT, Jean-Pierre. Mito y sociedad en la Grecia Antigua. Madrid: Siglo XXI, 1982.

VEZUB, Julio. La vida social de las cosas y los artefactos-documentos del Museo de Carmen de Patagones. Corpus, Mendoza: IANIGLA, v. 2, n. 1, 2012. Disponible en: http://corpusarchivos.revues.org/1083. Acceso en: 9 sep. 2016.

Recebido em 22/05/2018

Aceito em 19/09/2018 